\title{
Achievement of antioxidants from Abelmoschus esculentus L. seeds using ultrasound-assisted extraction optimized by the help of experimental design approach
}

\author{
Merve Bat-Özmatara ${ }^{1,{ }^{*}}$ and Şule Dinç-Zor $\oplus^{2}$

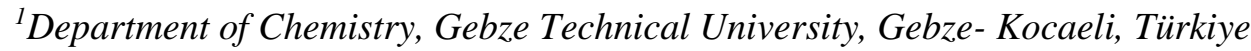 \\ ${ }^{2}$ Department of Chemistry, Yildiz Technical University, Davutpasa Campus, Istanbul, Türkiye
}

(Received July 29, 2020; Revised October 05, 2020; Accepted October 08, 2020)

\begin{abstract}
Developments of food supplements and nutraceuticals from different natural origins require the use of some extraction methods. The success of the procedure relies on theefficiency of the extraction methods. Therefore, extraction methods need to be optimized. This work aimed for the determination of optimal conditions of ultrasonicassisted extraction (UAE) of antioxidant constituents from okra (Abelmoschus esculentus L.) seeds which contain high contents of polysaccharides, polyphenols and flavonoids using response-surface methodology based on BoxBehnken experimental design (BBD). The independent variables of UAE were extraction time (Et, 10-20 min), extraction solvent composition (EC, 50-100\% methanol) and extraction solvent volume (EV, 10-20 mL). 2,2diphenyl-1-picrylhydrazyl (DPPH) radical-scavenging activity, 2,2'-azinobis- (3-ethylbenzothiazoline-6-sulfonic acid) (ABTS) radical-scavenging activity and N,N-dimethyl-p-phenylenediamine dihydrochloride (DMPD) radicalscavenging activity were dependent variables. Optimal extraction conditions for UAE from okra seed were: $20 \mathrm{~mL}$ volume of 70\% methanol at 10 min extraction time for DPPH inhibition; $20 \mathrm{~mL}$ volume of $50 \%$ methanol at 20 min for ABTS inhibition; $15 \mathrm{~mL}$ volume of 55\% methanol at $12 \mathrm{~min}$ for DMPD inhibition. Under these optimum extraction conditions, the effectiveness of UAE of okra seed was successfully revealed. So, this practical extraction technique can be widely used for the achievement of dietary supplements and nutraceuticals.
\end{abstract}

Keywords: Abelmoschus esculentus $L$. seed; okra; ultrasound-assisted extraction; box-behnken design; response surface methodology. @ 2020 ACG Publications. All rights reserved.

\section{Introduction}

The oxygen element, which has an important place in the metabolism of aerobic organisms, can trigger negative reactions and cause the formation of reactive oxygen species like singlet oxygen, hydrogen peroxide, hydroperoxyl radicals.

Antioxidants are chemical compounds used to prevent oxidation of lipids, sugars, proteins and DNA by the mechanisms of converting reactive oxygen species to non-radical species -depending on the antioxidants included- and by breaking mechanisms of the auto-oxidative chain reaction initiated by reactive oxygen species [1,2]. Nature is always an important and rich resource that can be used as healthenhancing agents. These natural sources can be fruits, vegetables, herbs, spices and medicinal plants that have extensive health promoting potentials [3]. Thanks to polyphenols (phenolic acids,

\footnotetext{
*Corresponding author E-Mail: mervebatt@ gmail.com
} 
proanthocyanidins, catechins, anthocyanins, lignans), carotenoids (xanthophylls and carotenes) and vitamins (vitamin $\mathrm{E}$ and $\mathrm{C}$ ), plant materials contain various biological effects. One of the most beneficial effects of these natural sources is that they have antioxidant properties [4].

Okra (Abelmoschus esculentus L.) is a vegetable belonging to the Malvaceae family commonly found in many regions [5,6]. Okra contains protein, unsaturated fatty acids, vitamin $\mathrm{C}$, phenolic compounds (flavonol derivatives and oligomeric catechins), folates and minerals such as iron, zinc, manganese and calcium [7]. Okra seeds also have antioxidant, hepatoprotective, anticancer, antidiabetic and neuroprotective activities [8].

Literature survey has revealed that various extraction techniques such as soxhlet, maceration, micro-wave assisted, ultrasound-assisted and supercritical fluid extraction are used to extract bioactive compounds from okra seeds, buds and leaves [3,9-14]. While soxhlet extraction has some disadvantages due to the long time required and the use of large amounts of organic solvent, ultrasound-assisted extraction (UAE) has many advantages due to the use of less solvent, low temperature operation, protection of plant structures, repeatability and high efficiency. For the effective UAE process, independent variables such as type of extraction solvent, solvent ratio and volume and sonication time must be optimized, which results in to have maximum yield of the bioactive compounds. In the literature, there is no study on optimization of the UAE conditions to extract antioxidants from Abelmoschus esculentus $L$. seeds.

Response surface methodology (RSM), based on the suitability of a polynomial equation to experimental data is a multivariable technique that can evaluate the effects and interactions of independent variables [15]. RSM has been preferred in the optimization step which is desired to be low cost, less solvent and material consumption in less time [16,17]. The aim of this study is to optimize the levels of these variables at the same time to achieve the best system performance.

In this study, the determination of optimal UAE conditions for superior yield of antioxidants from Abelmoschus esculentus $L$. seeds was presented by RSM approach including Box-Behnken experimental design (BBD) with three variables (extraction time, extraction solvent composition and volume).

\section{Experimental}

\subsection{Instrumentation}

Extraction of Abelmoschus esculentus L. seeds was done with a Caliskan ultrasonic bath with a constant frequency of $40 \mathrm{kHz}$ and a power setting of $60 \mathrm{~W}$. The antioxidant activity of Abelmoschus esculentus L.seed extracts was measured using a UV-Vis spectrophotometer (SpectraMax Plus 384 Microplate Reader, California, USA). A vortex mixer, model IKA MS3 which is from Germany was used.

\subsection{Materials and Chemicals}

Abelmoschus esculentus $L$. seeds were bought from herbalist in Istanbul, Turkey. 1,1-diphenyl-2picryl-hydrazyl (DPPH), [2,2'- azinobis- (3-ethylbenzothiazoline-6-sulfonic acid)](ABTS), potassium persulfate $\left(\mathrm{K}_{2} \mathrm{~S}_{2} \mathrm{O}_{8}\right)$, iron (III) chloride $\left(\mathrm{FeCl}_{3}\right)$, were purchased from Sigma. N,N-dimethyl-pphenylenediamine dihydrochloride (DMPD), ethanol, methanol, acetic acid and sodium acetate were purchased from Merck. All solvents were of analytical grade.

\subsection{Response Surface Optimization of Ultrasound-assisted Extraction (UAE)}

In this study, response surface methodology was performed to determine the optimum conditions of extractions of antioxidants from okra seeds. The Box-Behnken experimental design (BBD) was used at three levels with three independent variables by using the StatGraphics Centurion program (StatPoint, Inc., Warrenton, USA). Experimental ranges of the variables were selected according to preliminary studies (Table 1). As shown in Table 1, antioxidant content of $1000 \mathrm{mg}$ of the seeds of Abelmoschus esculentus L.was extracted at different time intervals (Et; 10,15 or $20 \mathrm{~min}$ ) with different extraction solvent composition (EC; 50\% methanol, $75 \%$ methanol or $100 \%$ methanol) and different extraction solvent volume $(\mathrm{EV} ; 10,15$ or $20 \mathrm{~mL})$ in ultrasonic bath $(40 \mathrm{kHz})$ at room temperature with shaking in a 
100-mL beaker. 15 experimental runs were carried out by BBD (Table 2). We would also like to mention that since the seeds were dry and so hard, soaking them in extraction solvent for a while increased the efficiency of UAE technique. After extraction trials, seeds were removed by filtration and the solvent was evaporated. Dried extracts were diluted in suitable solvent prior to antioxidant capacity tests. The responses of \% inhibitions of DPPH, ABTS and DMPD using experimental matrix are given in Table 2. Variance of analysis (ANOVA) was used to examine the effects of variables and their interactions on the responses and to determine models of the extraction conditions.

\subsection{Determination of Antioxidant Activity}

\subsubsection{DPPH Free Radical Scavenging Activity}

Assay for DPPH free radical scavenging activity is often used to evaluate the antioxidant capacity of compounds. The Brand-Williams method was used to test whether sample will bleach the stable DPPH radical. Thus, the DPPH radical scavenging activity was measured [18]. $0.75 \mathrm{~mL}$ of plant extract was added over $1.50 \mathrm{~mL}$ of DPPH solution prepared in ethanol $(0.05 \mathrm{mM})$. The mixture was kept at room temperature for 30 minutes after shaking vigorously. After 30 minutes, the absorbance at $517 \mathrm{~nm}$ was measured in the UV-Vis spectrophotometer. The scavenging activity of DPPH radical was calculated using the following formula:

$$
D P P H \text { scavenging }(\%)=\left[\frac{\text { Acontrol-Asample }}{\text { Acontrol }}\right] \times 100
$$

Herein, $A_{\text {control }}$ shows the absorbance of the control (DPPH solution without sample) and $A_{\text {sample }}$ shows the absorbance of the test sample.

\subsubsection{ABTS Radical Scavenging Activity}

This method, developed by Arnao et al, is based on the reduction of radical and color loss by adding antioxidants on the $\mathrm{ABTS}^{-+}$radical cation formed by $\mathrm{K}_{2} \mathrm{~S}_{2} \mathrm{O}_{8}$ oxidation of ABTS [2,2'-azinobis-(3ethylbenzothiazoline-6-sulfonic acid)]. Blue/green colored $\mathrm{ABTS}^{\cdot+}$ radical has strong absorption in 600$750 \mathrm{~nm}[19]$.

After mixing $7.4 \mathrm{mM}$ ABTS solution and $2.6 \mathrm{mM}$ potassium persulfate solution equally, it was kept in the dark for 12 hours at room temperature. $1 \mathrm{~mL}$ of the ABTS radical solution was diluted with an absorbance of $1.1 \pm 0.02$ at a wavelength of $734 \mathrm{~nm}$ in the spectrophotometer by adding about $60 \mathrm{~mL}$ of methanol. $150 \mu \mathrm{L}$ of sample solutions, $2850 \mu \mathrm{L}_{\text {of }} \mathrm{ABTS}^{\circ+}$ radical solution were left in the incubation for 2 hours in the dark. The control solution was prepared using distilled water instead of the sample. The absorbance at the wavelength of $734 \mathrm{~nm}$ was measured in the spectrophotometer. In the calculations, $\mathrm{ABTS} \%$ radical scavenging effect was found with the following formula.

$$
\operatorname{ABTS}^{\cdot+} \text { scavenging }(\%)=\left[\frac{\text { Acontrol-Asample }}{\text { Acontrol }}\right] \times 100 \quad(\text { Eq.2) }
$$

Here, $\mathrm{A}_{\text {control }}$ shows the absorbance of the control (ABTS solution without sample) and $\mathrm{A}_{\text {sample }}$ shows the absorbance of the test sample.

\subsubsection{DMPD Radical Scavenging Activity}

The method developed by Fogliano et al. was applied for this antioxidant capacity test [20]. DMPD turns into cation radical form $\left(\mathrm{DMPD}^{*+}\right)$ in acidic $\mathrm{pH}$ or in the presence of oxidant. After $100 \mathrm{mM}$ DMPD solution was prepared, radical was formed by adding $100 \mathrm{~mL}$ of $0.1 \mathrm{M}$ acetate buffer (pH 5.3) and $0.2 \mathrm{~mL}$ of $0.05 \mathrm{M} \mathrm{FeCl}_{3}$ onto $1 \mathrm{~mL}$ of this solution. Next, sample solution or control solution which is prepared by replacing the sample with water were added. After 10 minutes, the absorbance at the $505 \mathrm{~nm}$ wavelength was measured on the spectrophotometer. DMPD ${ }^{*+}$ radical scavenging activity was calculated according to the formula below. 


$$
\mathrm{DMPD}^{*+} \text { scavenging }(\%)=\left[\frac{\text { Acontrol-Asample }}{\text { Acontrol }}\right] \times 100 \quad \text { (Eq. 3) }
$$

Herein, $\mathrm{A}_{\text {control }}$ shows the absorbance of the control (DMPD solution without sample) and $\mathrm{A}_{\text {sample }}$ shows the absorbance of the test sample.

Table 1. Independent variables of UAE and their levels

\begin{tabular}{|c|c|c|c|c|c|}
\hline \multirow{2}{*}{$\begin{array}{l}\text { Independent } \\
\text { variable }\end{array}$} & \multirow[t]{2}{*}{ Symbol } & \multirow[t]{2}{*}{ Unit } & \multicolumn{3}{|c|}{ Levels } \\
\hline & & & $(-1)$ & $(0)$ & $(+1)$ \\
\hline Extraction time & $\mathrm{Et}$ & $\min$ & 10 & 15 & 20 \\
\hline $\begin{array}{l}\text { Extraction solvent } \\
\text { composition } \\
\text { Extraction solvent }\end{array}$ & $\mathrm{EC}$ & $\%$ Methanol & 50 & 75 & 100 \\
\hline volume & $\mathrm{EV}$ & $\mathrm{mL}$ & 10 & 15 & 20 \\
\hline
\end{tabular}

Table 2. The responses of \% inhibitions of DPPH, ABTS and DMPD based on BBD in the optimization of UAE

\begin{tabular}{ccccccc}
\hline & & & & Response & & \\
Trials & $\begin{array}{c}\text { Et } \\
(\mathbf{m i n})\end{array}$ & $\begin{array}{c}\text { EC } \\
(\text { \% Methanol) }\end{array}$ & $\begin{array}{c}\text { EV } \\
(\mathbf{m L})\end{array}$ & $\begin{array}{c}\text { DPPH } \\
\text { Y1 }\end{array}$ & $\begin{array}{c}\text { ABTS } \\
\text { Y2 }\end{array}$ & $\begin{array}{c}\text { DMPD } \\
\text { Y3 }\end{array}$ \\
\hline 1 & -1 & -1 & 0 & 56 & 54 & 78 \\
2 & 1 & -1 & 0 & 62 & 77 & 75 \\
3 & -1 & 1 & 0 & 42 & 12 & 9 \\
4 & 1 & 1 & 0 & 46 & 9 & 9 \\
5 & -1 & 0 & -1 & 70 & 16 & 44 \\
6 & 1 & 0 & -1 & 82 & 15 & 59 \\
7 & -1 & 0 & 1 & 70 & 33 & 63 \\
8 & 1 & 0 & 1 & 80 & 33 & 52 \\
9 & 0 & -1 & -1 & 57 & 57 & 65 \\
10 & 0 & 1 & -1 & 40 & 6 & 5 \\
11 & 0 & -1 & 1 & 58 & 61 & 78 \\
12 & 0 & 1 & 1 & 45 & 12 & 10 \\
13 & 0 & 0 & 0 & 71 & 26 & 67 \\
14 & 0 & 0 & 0 & 71 & 23 & 68 \\
15 & 0 & 0 & 0 & 69 & 27 & 67 \\
\hline
\end{tabular}

\section{Results and discussion}

\subsection{Response Surface Analysis of DPPH}

To determine optimum UAE conditions, the effects of extraction time, extraction solvent composition and extraction solvent volume on DPPH radical scavenging activity (Y1) were investigated by using BBD. In the preliminary studies, it was seen that the treatments of the seeds such as only soaking of the seeds to extraction solvent without powdering facilitate to have more efficient UAE process. Therefore, duration of soaking before extraction was investigated and $4 \mathrm{~h}$ was found to be enough.

The ANOVA results and the regression model of DPPH inhibition are represented in Table 3. This test reveals the most important effects and interactions by statistical calculations. Since p-value was less than 0.05 in the ANOVA table, Et and EC were statistically significant at a 95\% confidence level. EV in the selected levels was negligible on DPPH radical scavenging activity. The F-test was also used to estimate the statistical significance of all terms in the model equation. While Et has a positive effect on the response, EC has a negative effect, which leads to have a higher DPPH inhibition by increasing 
extraction time. In addition the second order effects of Et and EC play important role on DPPH inhibition. The determination coefficient $\left(\mathrm{R}^{2}\right)$ and adjusted determination coefficient $\left(\mathrm{R}^{2}\right.$ adj $)$ for the quadratic model were found to be 0.9882 and 0.9670 , respectively, which revealed a high accuracy of the models. Furthermore, the p-value of lack of fit was insignificant for DPPH inhibition $(\mathrm{P}>0.05)$, indicating that the model fits the experimental results accurately.

Three-dimensional (3D) response surface graphs based on a quadratic model are useful for the achievement of high response depending on the processing variables. From the obtained regression model, response surface graphs belonging to inhibition of DPPH were drawn for each variable in Figure 1. The optimal values of the variables were calculated using the estimated quadratic model. According to these calculations, maximum DPPH inhibition can be achieved with methanol:water (70:30, v/v) and extraction solvent volume of $10 \mathrm{~mL}$ at an extraction time of $20 \mathrm{~min}$.
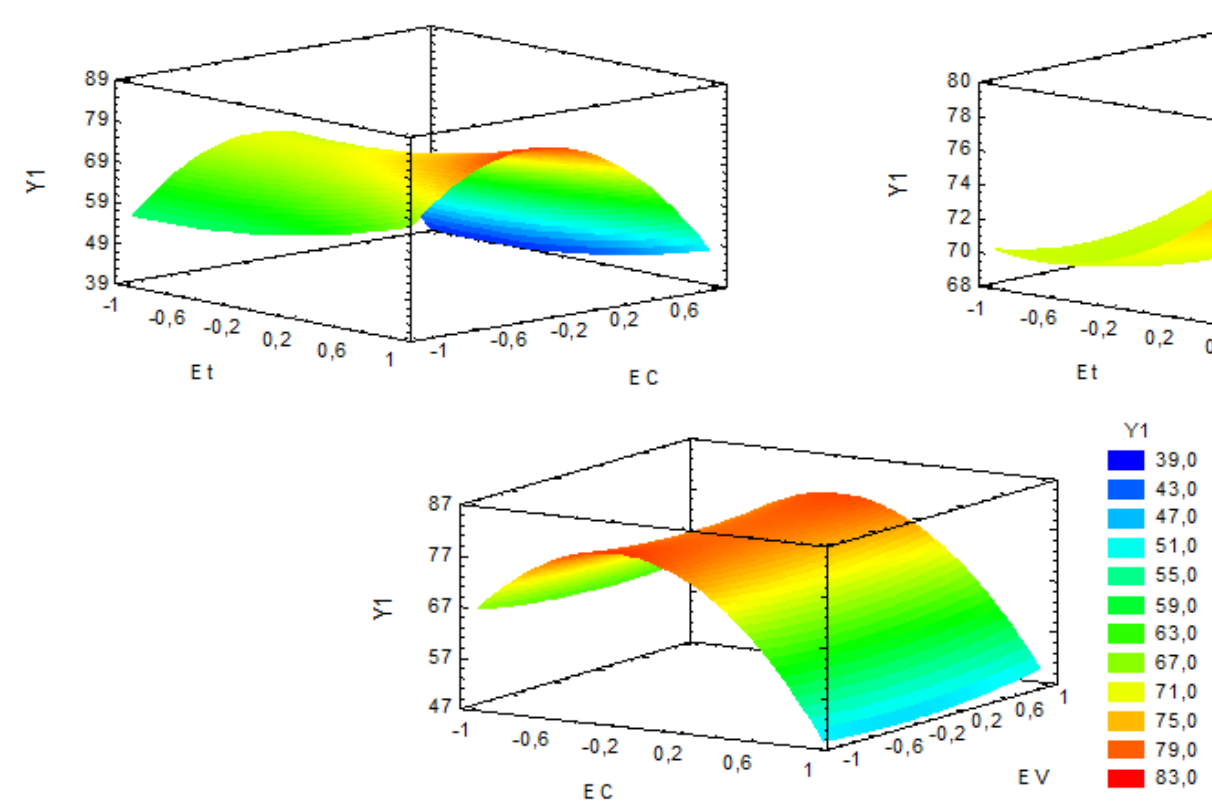

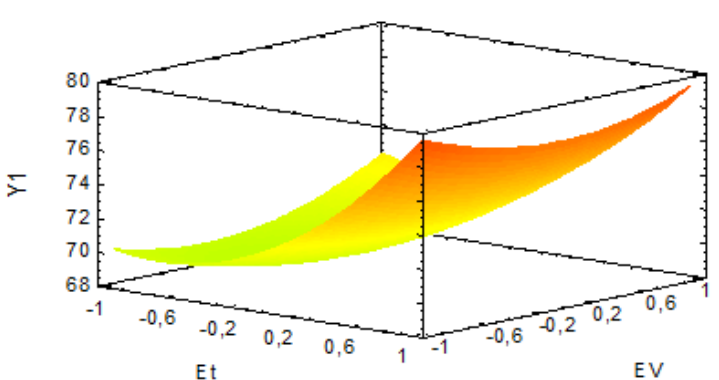

Figure 1. Response surface graphs for DPPH inhibition (Y1) depending on the processing variables (the third variable was fixed at its optimum value)

\subsection{Response Surface Analysis of ABTS}

The investigated variables; the effects of extraction time, extraction solvent composition and extraction solvent volume were optimized by Box-Behnken experimental design with 3-level and total 15 experiments for ABTS radical scavenging activity. The matrix of experimental conditions and the observed responses for ABTS inhibition were given in Table 2. Table 4 also shows the statistical summary of quadratic model suggested by the software. It can be seen that the most effective variables on ABTS inhibition are extraction solvent composition and extraction solvent volume when $F$ and $p$ values were assessed. In addition, the second order effect of extraction solvent composition and interaction between extraction time and extraction solvent composition were found significant. $\mathrm{R}^{2}$ and $\mathrm{R}_{\text {adj }}^{2}$ for the quadratic model were very close to $1\left(\mathrm{R}^{2}=0.9768\right.$ and $\left.\mathrm{R}_{\text {adj }}=0.9349\right)$, suggesting the regression model can perfectly explain the UAE process (Table 4). Moreover, non-significant lack of fit showed the model for ABTS inhibition was in good agreement with the real data.

As shown in Figure 2, at a high extraction solvent composition in terms of methanol, ABTS inhibition slightly decreased with the increase of methanol ratio. However, as extraction volume increases, this response go up since it has positive effect on ABTS inhibition. It was concluded that extraction time in the selected levels was non-significant. Due to longer extraction time, antioxidant substances may be destroyed by the powerful energy of the ultrasonic waves, thus 20 min was considered to be enough for 
extraction process. The optimal UAE conditions for the extraction of antioxidants were selected at $20 \mathrm{~min}$ of extraction time, $50 \%$ methanol concentration, and $20 \mathrm{~mL}$ extraction solvent volume.

Table 3. Analysis of variance for DPPH inhibition results obtained through BBD

\begin{tabular}{llllllll}
\hline Source & $\begin{array}{l}\text { Sum of } \\
\text { Squares }\end{array}$ & Df $^{\mathbf{a}}$ & $\begin{array}{l}\text { Mean } \\
\text { Square }\end{array}$ & F-Ratio & P-Value & $\begin{array}{l}\text { Regression } \\
\text { coefficient }\end{array}$ & Effect \\
\hline $\mathrm{Et}$ & 130.411 & 1 & 130.411 & 97.81 & $0.0101^{*}$ & 4.04 & 8.08 \\
$\mathrm{EC}$ & 441.045 & 1 & 441.045 & 330.78 & $0.0030^{*}$ & -7.42 & -14.85 \\
$\mathrm{EV}$ & 2.53125 & 1 & 2.53125 & 1.90 & 0.3022 & 0.56 & 1.12 \\
$\mathrm{Et}^{2}$ & 40.1078 & 1 & 40.1078 & 30.08 & $0.0317^{*}$ & 3.29 & 6.59 \\
$\mathrm{EC}^{2}$ & 1799.96 & 1 & 1799.96 & 1349.97 & $0.0007^{*}$ & -22.07 & -44.15 \\
$\mathrm{EV}^{2}$ & 11.2539 & 1 & 11.2539 & 8.44 & $0.1009^{*}$ & 1.74 & 3.49 \\
$\mathrm{Et.EC}$ & 1.69 & 1 & 1.69 & 1.27 & 0.3772 & -0.65 & -1.3 \\
Et.EV & 1.5625 & 1 & 1.5625 & 1.17 & 0.3922 & -0.63 & -1.25 \\
EC.EV & 4.0 & 1 & 4.0 & 3.00 & 0.2254 & 1.0 & 2.0 \\
Lack-of-fit & 27.2375 & 3 & 9.07917 & 6.81 & 0.1307 & & \\
Pure error & 2.66667 & 2 & 1.33333 & & & & \\
Total (corr.) & 2539.34 & 14 & & & & &
\end{tabular}

${ }^{\mathrm{a} D f}$ : Degree of freedom. ${ }^{*}$ Significant factor at $\alpha=0.05$.

$\mathrm{R}^{2}=0.9882, \mathrm{R}_{\text {adj }}^{2}=0.9670$.

constant for regression model: 70.33 .

Table 4. Analysis of variance for ABTS inhibition results obtained through BBD

\begin{tabular}{llllllll}
\hline Source & $\begin{array}{l}\text { Sum of } \\
\text { Squares }\end{array}$ & Df $^{\mathrm{a}}$ & $\begin{array}{l}\text { Mean } \\
\text { Square }\end{array}$ & F-Ratio & P-Value & $\begin{array}{l}\text { Regression } \\
\text { coefficient }\end{array}$ & Effect \\
\hline Et & 45.125 & 1 & 45.125 & 10.41 & 0.0841 & 2.37 & 4.75 \\
$\mathrm{EC}$ & 5512.5 & 1 & 5512.5 & 1272.12 & $0.0008^{*}$ & -26.25 & -52.5 \\
$\mathrm{EV}$ & 253.125 & 1 & 253.125 & 58.41 & $0.0167^{*}$ & 5.62 & 11.25 \\
$\mathrm{Et}^{2}$ & 7.85256 & 1 & 7.85256 & 1.81 & 0.3105 & 1.46 & 2.92 \\
$\mathrm{EC}^{2}$ & 463.853 & 1 & 463.853 & 107.04 & 0.0092 & 11.20 & 22.41 \\
$\mathrm{EV}^{2}$ & 23.8526 & 1 & 23.8526 & 5.50 & 0.1436 & -2.54 & -5.08 \\
Et.EC & 169.0 & 1 & 169.0 & 39.00 & $0.0247^{*}$ & -6.5 & -13.0 \\
Et.EV & 0.25 & 1 & 0.25 & 0.06 & 0.8326 & 0.25 & 0.5 \\
EC.EV & 1.0 & 1 & 1.0 & 0.23 & 0.6784 & 0.5 & 1.0 \\
Lack-of-fit & 145.75 & 3 & 48.5833 & 11.21 & 0.0830 & & \\
Pure error & 8.66667 & 2 & 4.33333 & & & & \\
Total (corr.) & 6644.93 & 14 & & & & & \\
\hline Df: Degree & & & & & & & \\
\hline
\end{tabular}

${ }^{\mathrm{a} D f}$ : Degree of freedom.

$*$ Significant factor at $\alpha=0.05$.

$\mathrm{R}^{2}=0.9768, \mathrm{R}_{\text {adj }}^{2}=0.9349$.

constant for regression model: 25.33 . 

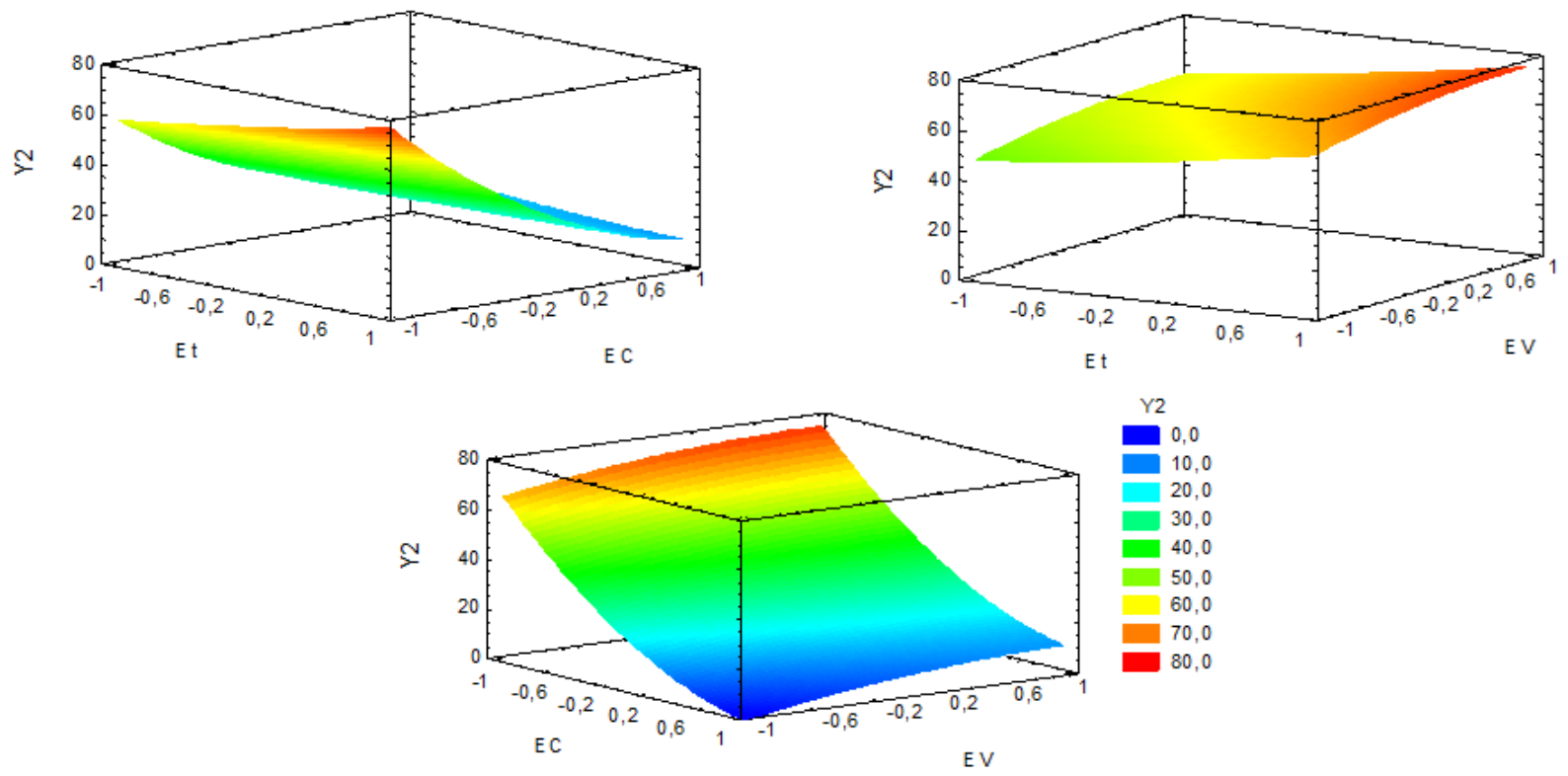

Figure 2. Response surface graphs for ABTS inhibition (Y2) depending on the processing variables (the third variable was fixed at its optimum value)

\subsection{Response Surface Analysis of DMPD}

The quadratic polynomial model based on multiple regression analysis for three response variables was presented in Table 5 by using ANOVA. Determination coefficient of the model; $\mathrm{R}^{2}$ was 0.9982. In this case, the model was well matched with the experimental data. The non-significant lack of fit value $(\mathrm{P}>0.05)$ also shows the fitness of the model. In the tested range, EC and EV as main effects and quadratic effects of all variables $\left(\mathrm{Et}^{2}, \mathrm{EC}^{2}\right.$ and $\left.\mathrm{EV}^{2}\right)$ had a significant effect on DMPD inhibition. Interactions between extraction time and extraction solvent volume (Et.EV) and extraction solvent composition and extraction solvent volume (EC.EV) were also found significant. Table 5 reveals that extraction time in the studied range did not have a significant effect on DMPD inhibition.

Table 5. Analysis of variance for DMPD inhibition results obtained through BBD

\begin{tabular}{llllllll}
\hline Source & $\begin{array}{l}\text { Sum of } \\
\text { Squares }\end{array}$ & Df & $\begin{array}{l}\text { Mean } \\
\text { Square }\end{array}$ & F-Ratio & P-Value & $\begin{array}{l}\text { Regression } \\
\text { coefficient }\end{array}$ & Effect \\
\hline Et & 0.045 & 1 & 0.045 & 0.14 & 0.7485 & 0.075 & 0.15 \\
EC & 8672.44 & 1 & 8672.44 & 26017.34 & $0.0000^{*}$ & -32.92 & -65.85 \\
EV & 112.5 & 1 & 112.5 & 337.50 & $0.0029^{*}$ & 3.75 & 7.5 \\
$\mathrm{Et}^{2}$ & 86.5541 & 1 & 86.5541 & 259.66 & $0.0038^{*}$ & -4.84 & -9.68 \\
$\mathrm{EC}^{2}$ & 1453.63 & 1 & 1453.63 & 4360.89 & $0.0002^{*}$ & -19.84 & -39.68 \\
$\mathrm{EV}^{2}$ & 235.816 & 1 & 235.816 & 707.45 & $0.0014^{*}$ & -7.99 & -15.98 \\
Et.EC & 1.69 & 1 & 1.69 & 5.07 & 0.1532 & 0.65 & 1.3 \\
Et.EV & 169.0 & 1 & 169.0 & 507.00 & $0.0020^{*}$ & -6.5 & -13.0 \\
EC.EV & 16.0 & 1 & 16.0 & 48.00 & $0.0202^{*}$ & -2.0 & -4.0 \\
Lack-of-fit & 18.19 & 3 & 6.06333 & 18.19 & 0.0526 & & \\
Pure error & 0.666667 & 2 & 0.333333 & & & & \\
Total (corr.) & 10629.8 & 14 & & & & & \\
\hline
\end{tabular}

${ }^{\mathrm{a} D f}$ : Degree of freedom.

$*$ Significant factor at $\alpha=0.05$.,

$\mathrm{R}^{2}=0.9982, \mathrm{R}_{\text {adj }}^{2}=0.9950$,

constant for regression model: 67.4 
To reveal the relationship between DMPD inhibition response and experimental levels of the selected variables, 3D surface graphs were constructed according tothe quadratic polynomial model equations of Table 5 (Figure 3). It can be clearly seen from the figure that, the decrease of methanol ratio in extraction solvent could improve UAE, which results in increasing on DMPD radical scavenging activity. In the light of all information, the UAE conditions for maximum of DMPD inhibition were as follows: extraction time $12 \mathrm{~min}$, methanol concentration 55\% and extraction solvent volume $15 \mathrm{~mL}$.
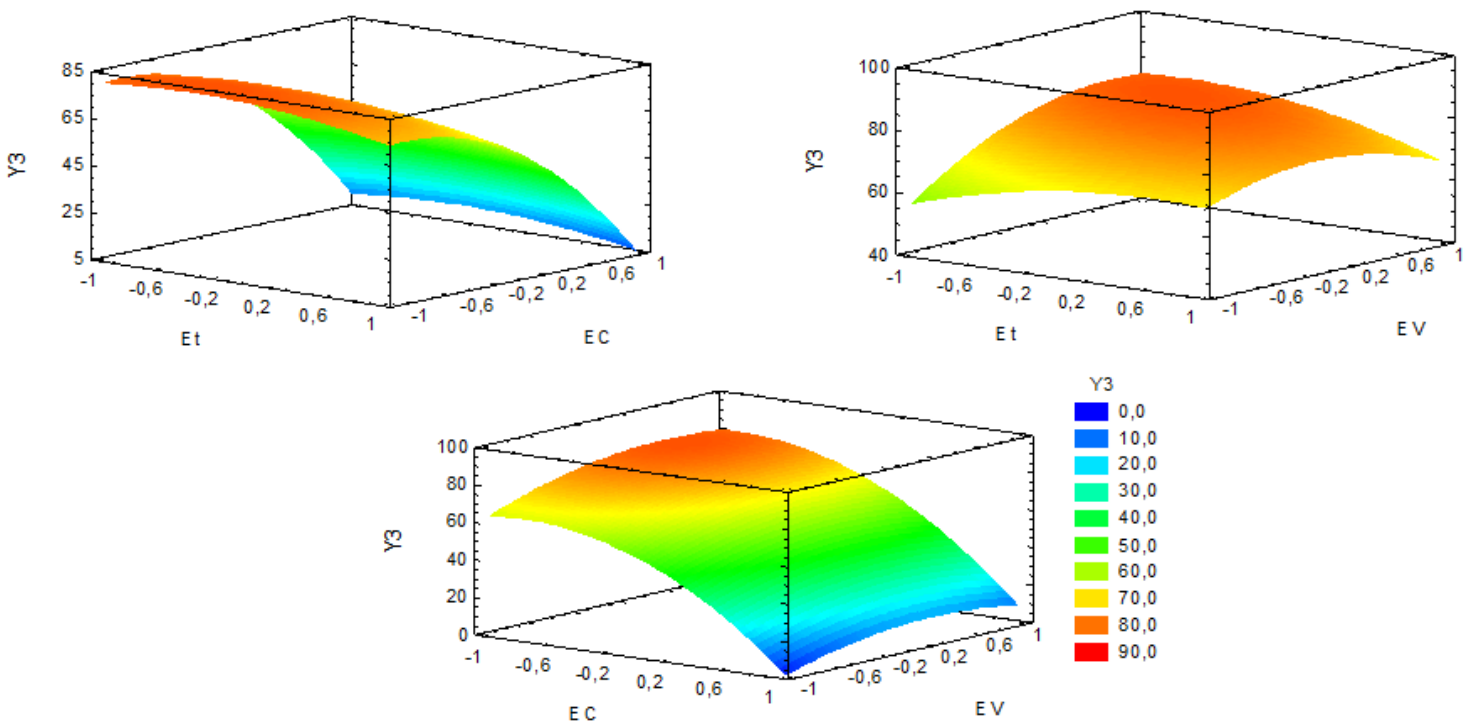

Figure 3. Response surface graphs for DMPD inhibition (Y3) depending on the processing variables (the third variable was fixed at its optimum value)

\section{Conclusions}

In this study, the optimal UAE conditions were developed for the extraction of antioxidants in okra seeds by using experimental design. UAE is a quick and convenient technique for the extraction of antioxidant substances and it can be used instead of conventional extraction methods which are timeconsuming and requiring plenty of solvent. The optimal condition was found to be: for DPPH inhibition using $20 \mathrm{~mL}$ volume of $70 \%$ methanol at 10 min extraction time; for ABTS inhibition using $20 \mathrm{~mL}$ volume of $50 \%$ methanol at $20 \mathrm{~min}$; for DMPD inhibition using $15 \mathrm{~mL}$ volume of $55 \%$ methanol at $12 \mathrm{~min}$. Soaking the seeds in extraction solvent for a while before extraction process led to increasing of the efficiency of UAE. Nutraceuticals or food supplements which are needed for healthy life can be easily prepared in a short time by the extraction of antioxidants from okra seeds that have a rich antioxidant content.

\section{Acknowledgements}

The authors would like to thank Prof. Dr. Ayşegül Peksel for the supply of chemical substances and her valuable suggestions.

\section{ORCID}

Merve Bat Özmatara: 0000-0002-6912-8825

Şule Dinç Zor: 00000-0002-9703-6768

\section{References}

[1] R. Jagessar (2019). Antioxidant properties of plant extracts, Pharma. Anal. Acta. 1, 18-21.

[2] M.F. Li, P.W. Pare, J.L. Zhang, T.L. Kang, Z.Zhang, D.L. Yang, K.P. Wang and H.Xing (2018). Antioxidant capacity connection with phenolic and flavonoid content in Chinese medicinal herbs Rec.Nat.Prod. 12, 240-251. 
[3] D. Xu, Y. Li, X. Meng, T. Zhou, Y. Zhou, J. Zheng, J. Zhang and H. Li (2017). Natural antioxidants in foods and medicinal plants: extraction, assessment and resources, Int. J. Mol. Sci. 18, 96 (32 pages).

[4] H. Han, H. Yilmaz and İ. Gulcin (2018). Antioxidant activity of Flaxseed (Linum usitatissimum L.) shell and Analysis of Its Polyphenol Contents by LC-MS/MS, Rec.Nat.Prod. 12, 397-402.

[5] S. Petropoulos, A. Fernandes, L. Barros, A. Ciric, M. Sokovic and I. Ferreira (2017).The chemical composition, nutritional value and antimicrobial properties of Abelmoschus esculentus seeds, Food Funct. 8, 4733-4743.

[6] Y. Liu, J. Qi, J. Luo, W. Qin, Q. Luo, Q. Zhang, D. Wu, D. Lin, S. Li, H. Dong, H. Chen and D. Chen (2019). Okra in food field: nutritional value, health benefits and effects of processing methods on quality, Food Rev. Int. 1-24. doi: doi.org/10.1080/87559129.2019.1695833

[7] S. Petropoulos, A. Fernandes, L. Barros and I. Ferreira (2018). Chemical composition, nutritional value and antioxidant properties of Mediterranean okra genotypes in relation to harvest stage, Food Chem. 242, 466-474.

[8] H. Gemede, N. Ratta, G. Haki, A. Woldegiorgis and F. Beyene (2015). Nutritional quality and health benefits of "Okra'" (Abelmoschus esculentus): A review, Int. J. Food Sci. Nutr. 4, 208-2015.

[9] C. Acikgoz, A. Borazan, E. Andoglu and D. Gokdai (2016). Chemical composition of Turkish seeds (Hibiscus esculenta L.) and the total phenolic content of okra seeds flour, ESTUJST-A. 17, 766-774.

[10] H. Faisal and S. Handayani (2019). Comparison of antioxidant activity of ethanol extract of fruit and okra leaves( Abelmoschus esculentus L. Moench) with DPPH and ABTS methods, Indonesian J. Pharmaceut. Clin. Res. 2, 6-13.

[11] S. Vandavasi, G. Surendra, A. Male, A. Saikiran, I. Raj and A. Naidu (2018). In vitro antioxidant potential screening of different leaf extracts of Abelmoschus esculentus Linn, Int. J. Pharm. Sci. Res. 9, 5253-5257.

[12] K. Wang, M. Li, X. Wen, X. Chen, Z. He and Y. Ni (2018). Optimization of ultrasound-assisted extraction of okra (Abelmoschus esculentus (L.) Moench) polysaccharides based on response surface methodology and antioxidant activity, Int. J. Biol. Macromol. 114, 1056-1063.

[13] Q. Yuan, S. Lin, Y. Fu, X.R. Nie, W. Liu, Y. Su, Q.H. Han, L. Zhao, Q. Zhang, D. Lin, W. Qin and D. Wu (2019). Effects of extraction methods on the physicochemical characteristics and biological activities of polysaccharides from okra (Abelmoschus esculentus), Int. J. Biol. Macromol. 127, 178-186.

[14] Z. Dong, J.G. Zhang, K.W. Tian, W.J. Pan and Z.J. Wei (2014). The fatty oil from okra seed: Supercritical carbon dioxide extraction, composition and antioxidant activity, Curr. Top. Nutraceutical. Res. 12(3), 7584.

[15] Montgomery DC (2004). Design and analysis of experiments. Wiley, New York.

[16] M.A. Bezerra, R.E, Santelli, E.P. Oliveira, L.S. Villar and L.A. Escaleira (2008). Response surface methodology (RSM) as a tool for optimization in analytical chemistry, Talanta 76(5), 965-977.

[17] I.A.M. Ahmed, F. Al-Juhaimi, A.R. Adisa, O.Q. Adiamo, E.E. Babiker, M.A. Osman, K.G. Gassem, A.S. Hesham and M.A. Elkareem (2020). Optimization of ultrasound-assisted extraction of phenolic compounds and antioxidant activity from Argel (Solenostemma argel Hayne) leaves using response surface methodology (RSM), Int. J. Food. Sci. Technol. 1-10.

[18] N. R. Chamarthi, V. C. Ponne, H. B.Pulluru, J. D. Balija, S. R. Gutala, S. V. Kallimakula, V. Chintha and R. Wudayagir (2019). New symmetrical acyclic and alicyclic bisurea derivatives of 4,4 'methylenebis(phenyl isocyanate): Synthesis, characterization, bioactivity and antioxidant activity evaluation and molecular docking studies, Org.Commun. 11, 80-97

[19] L. Li, W. Du and W.Wang (2019). Evaluation of the antioxidative and anti-inflammatory effects of the extract of Ribes mandshuricum (Maxim.) Kom. leaves, Rec. Nat. Prod. 13, 141-155.

[20] V. Fogliano, V. Verde, G. Randazzo and A. Ritieni (1999). Method for measuring antioxidant capacity of wines, J. Agric. Food Chem. 47,1035-1040.

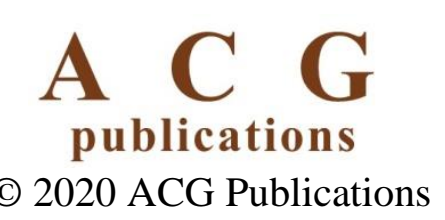

